\title{
Desafios e Perspectivas para a Proteção JuRisdicional do Ambiente URBANo
}

\section{Desafíos y Perspectivas para la Protección JuRisdiccional del Ambiente Urbano}

\section{Challenges and Perspectives for the Jurisdictional Protection of the Urban ENVIRONMENT}

\author{
Ailor Carlos Brandelli \\ Carlos Alberto Lunelli* \\ Julien Prieur ${ }^{* * *}$
}

\begin{abstract}
1 Introdução. 2 O desenvolvimento das cidades: da importância do trabalho ao caos social. $3 \mathrm{O}$ desafio da proteção jurisdicional do ambiente urbano e os entraves ideológicos. 4 As perspectivas para o desenvolvimento do ambiente urbano e sua proteção jurisdicional. 5 Conclusão. Referências.
\end{abstract}

\section{RESUMO}

Objetivo: $\mathrm{O}$ objeto deste artigo é analisar o ambiente urbano e as suas facetas, por meio de um recorte histórico do período da Revolução Industrial até o reconhecimento de

Doutor e Mestre em Direito Ambiental pela Universidade de Caxias do Sul (RS). Especialista em Direito Processual. Docente em cursos de graduação e especialização. Caxias do Sul, RS, BR. Email: <ailorbrandelli@gmail.com>. https://orcid.org/0000-0003-0006-5261

** Doutor e Mestre em Direito Público pela Universidade do Vale do Rio dos Sinos. Pós-doutor em Direito pela Universidade de Padova - Itália. Atualmente é professor titular da Universidade de Caxias do Sul, no Mestrado e Doutorado em Direito. Caxias do Sul, RS, BR. E-mail: <calunell@ucs.br>.https://orcid.org/0000-0002-4976-0719

${ }^{* * *}$ Doutor em Direito Público, com ênfase em Direito do Desenvolvimento Sustentável pela Université de Limoges - França, Faculté de Droit et Sciences Economiques. Mestre em Direito do Desenvolvimento Sustentável pela Université de Limoges - França. Université de Limoges - França, Faculté de Droit et Sciences Economiques. E-mail: <j.prieur@yahoo.fr>.https://orcid.org/0000-00018768-7914 
sua proteção na Carta Constitucional de 1988 e o posterior Estatuto da Cidade. Observam-se os entraves ideológicos da proteção ambiental, sentido tanto nas searas políticas quanto nas jurídicas, impondo a necessidade de fomentar instrumentos para a sua proteção jurisdicional.

Metodologia: A pesquisa que se apresenta estrutura-se a partir do método hermenêutico, método da compreensão, próprio e adequado para a investigação científica nas ciências do espírito. $\mathrm{O}$ método de procedimento utilizado é o monográfico, pela técnica de pesquisa em fontes bibliográficas e documentais, notadamente, explorando obras e autores que abordam a proteção do bem ambiental e o Direito Urbanístico. As técnicas de pesquisa compreenderam a revisão bibliográfica e a produção de resenhas e fichamentos, a partir da observação da trilogia dos manuais, das obras específicas e dos artigos científicos.

Resultados: Ficou demonstrado que a existência de normas constitucionais e as leis ordinárias hábeis à proteção do ambiente urbano carecem de efetividade, já que dependentes de decisões políticas e judiciais, que, por vezes, compreendem de forma diversa a finitude dos recursos e a proteção ambiental almejada pela sociedade, o que reclama uma nova postura, hábil a efetivar os reclames em prol do bem ambiental.

Contribuições: A abordagem identifica que a efetividade da proteção ambiental dos ambientes urbanos é, ainda, um dos maiores desafios da humanidade neste século, já que proteger o ambiente é garantir a manutenção da vida e das próprias relações sociais.

Palavras-chave: Ambiente. Ideologia. Jurisdição. Urbanismo.

\section{RESUMEN}

Objetivo: El objeto de este artículo es el de analizar el ambiente urbano y sus facetas, a través de un recorte histórico del período de la Revolución Industrial hasta el reconocimiento de su protección en la Carta Constitucional de 1988 y el posterior Estatuto de la Ciudad. Observa los obstáculos ideológicos de la protección ambiental, sentido tanto en los campos políticos como jurídicos, imponiendo la necesidad de fomentar instrumentos para su protección jurisdiccional.

Metodología: La pesquisa que se presenta se estructura a partir del método hermenéutico, método de la comprensión, propio y adecuado para la investigación científica en las ciencias del espíritu. El método de procedimiento utilizado es el monográfico, por la técnica de pesquisa en fuentes bibliográficas y documentales, notablemente, explorado obras y autores que abordan la protección del bien ambiental y del Derecho Urbanístico. Las técnicas de pesquisa comprendieron la revisión 
bibliográfica y la producción de reseñas y fichas, observada la trilogía de los manuales, obras específicas y artículos científicos.

Resultados: Quedo demostrado que la existencia de las normas y leyes ordinarias hábiles a la protección del ambiente urbano carecen de efectividad, ya que dependientes de decisiones políticas y judiciales, que, por veces, comprenden de manera diversa la finitud de los recursos y la protección ambiental deseada por la sociedad, lo que reclama una nueva postura, hábil a efectivar los reclames en favor del bien ambiental.

Contribuciones: El abordaje identifica que la efectividad de la protección ambiental de los ambientes urbanos es, todavía, uno de los mayores desafíos de la humanidad en este siglo, ya que proteger el ambiente es garantizar el mantenimiento de la vida y de las propias relaciones sociales.

Palabras clave: Ambiente. Ideología. Jurisdicción. Urbanismo.

\section{ABSTRACT}

Objective: The object of this article is to analyze the urban environment and its facets, through a historical snippet that goes from the Industrial Revolution to the recognition of its protection in the Constitutional Charter of 1988 and the subsequent City Statute. It observes the ideological obstacles to environmental protection, present in both political and legal fields, imposing the need to promote instruments for their judicial protection.

Methodology: The research presented is based on the hermeneutic method, a method of understanding, proper and suitable for scientific research in the sciences of the spirit. The method used for the procedure is the monographic one, by the technique of research in bibliographic and documentary sources, particularly, exploring works and authors that address the protection of the environmental assets and Urban Law. The research techniques included the bibliographic review and the production of reviews and records, by observing the trilogy of manuals, specific works and scientific articles.

Results: It's demonstrated that the existence of constitutional and ordinary laws standards capable of protecting the urban environment are ineffective, since they depend on political and judicial decisions, which sometimes understand differently the finitude of resources and the environmental protection desired by society, which demands a new approach, able to carry out the claims in favor of the environmental resources.

Contributions: The approach identifies that the effectiveness of the environmental protection of urban environments is, still, one of the greatest challenges of humanity in 
this century, since protecting the environment is to guarantee the maintenance of life and social relations.

Keywords: Environment. Ideology. Jurisdiction. Urbanism.

\section{INTRODUÇÃO}

A gestão dos espaços urbanos sempre foi desafiadora para própria sociedade, muito embora tal afirmação possa aparentar certa incoerência. Isso porque a organização de tais espaços não foi precedida de um planejamento necessário a alocar as pessoas, que, por vezes, vinham impulsionadas pela busca de trabalho ou de uma vida melhor, sem que, para isso, houvesse qualquer controle. Verifica-se com clareza que os espaços urbanos crescem de forma desordenada, por meio de um processo de exclusão, o que é sentido inclusive nos países mais desenvolvidos, já que a organização de tais espaços premia a condição financeira e social em detrimento da sustentabilidade.

O contexto da urbanização, em face do estudo entre o período da Revolução Industrial até o assento constitucional da Constituição Federal de 1988, consolidado pelos propósitos do Estatuto da Cidade, diante das observações das observações das dificuldades postas por elementos ideológicos da proteção ambiental, observado nas searas políticas e jurídicas, impondo a necessidade de fomentar instrumentos para a sua proteção jurisdicional, sendo relevante a pesquisa com o propósito de ampliar as reflexões na seara do Direito, a respeito dessa conduta de exclusão que se dá no desenvolvimento e crescimento das cidades.

O direito tem importante papel para equilibrar esse embate, promovendo o reconhecimento dos direitos fundamentais e sociais garantidos nas normas legais vigentes. No entanto, as decisões padecem de efetividade, conquanto permeadas de um componente ideológico afeto ao direito material e processual, já que o modelo existente atenta muito mais aos ditames processuais do que propriamente à resolução do litígio, comportando assim, pela via do debate apresentado, um novo modelo de compreensão e jurisdição, como desafio à proteção jurisdicional do ambiente urbano.

Esses espaços urbanos periféricos, que crescem desordenadamente e fomentam a exclusão social são dotados de invisibilidade na condição de atores ou de sujeitos de políticas públicas voltadas à gestão democrática das cidades, que modele território, ocupação e acesso de forma digna, reclamando, assim, uma reflexão jurídica e social sobre o tema, ao qual o presente estudo se propõe. 


\section{O DESENVOLVIMENTO DAS CIDADES: DA IMPORTÂNCIA DO TRABALHO AO CAOS SOCIAL}

As cidades representam a consolidação do propósito das pessoas em exercer na plenitude a propriedade privada e dela, além de estabelecer a habitação, impor seus interesses econômicos, políticos e sociais, de modo que "a cidade é a nova casa do homem, lugar de civilidade e meio de defesa do interesse comum do cidadão". (RECH; RECH, 2016, p. 23).

Esses interesses acabaram norteando o desenvolvimento e a organização dos territórios urbanos, nem sempre garantindo as condições mínimas de dignidade para todos os seus habitantes, impondo, assim, a necessária intervenção do Estado. Esse desenvolvimento, em grande parte, deu-se por meio de condutas e decisões que carregavam um propósito de exclusão dos citadinos, impondo aos mais pobres e desfavorecidos a habitação em áreas afastadas das elites, locais esses em que assentavam suas moradias, de modo que, quanto mais se consolidava a exclusão, mais marginalizados estavam aqueles que passavam a habitar os limites extremos do território urbano.

Os efeitos da exclusão foram mais sentidos com a afirmação do modelo capitalista, que demandou considerável mão de obra, vinda em sua maior parte de êxodo rural sem precedentes, já que a manufatura dos recursos ambientais ocorria principalmente nos grandes centros urbanos. A dinâmica dessa industrialização teve efeitos nefastos, produziu uma legião de desempregados, mutilados, inválidos e toda sorte de desafortunados, percebendo-se que a Revolução Industrial promoveu, ainda que de forma pouco ordenada, o fenômeno da urbanização das cidades. Os impactos ambientais então sentidos estavam diretamente relacionados às questões de urbanização dos grandes centros pela falta de saneamento e a poluição atmosférica decorrente da queima do carvão para aquecimento ou geração de energia. Na obra de Engels escrita em 1845, e intitulada "A Situação da Classe Trabalhadora na Inglaterra", descrevendo a situação do Velho Continente da época, o autor percebe que:

Habitualmente, as ruas não são planas nem calçadas, são sujas, tomadas por detritos vegetais e animais, sem esgotos ou canais de escoamento, cheias de charcos estagnados e fétidos. A ventilação na área é precária, dada a estrutura irregular do bairro e, como nesses espaços restritos vivem muitas pessoas, é fácil imaginar a qualidade do ar que se respira nessas zonas operárias (ENGELS, 2008, p. 70).

Essa condição insalubre, tanto do trabalho quanto da moradia, exteriorizou a situação dessa legião de trabalhadores esquecida pelo Estado, quer seja por não mais se prestar ao trabalho braçal, quer seja por escapar de seus olhos. No Brasil, a situação recebeu os mesmos contornos, todavia, em momento posterior. Para Mukai (2002, p. R. Opin. Jur., Fortaleza, ano 19, n. 31, p.175-195, maio/ago. 2021 • 179 
47): “[...] os efeitos da Revolução Industrial chegaram ao Brasil com algum atraso, e a urbanização acelerada, bem como suas consequências também chegaram aqui após alguns anos da influência que exerceram nos países desenvolvidos”.

Para Ermínia Maricato, o modelo gerou grandes mudanças sociais nesse período, impondo uma nova organização da vida familiar, que passa a incorporar a mulher no mercado de trabalho, concluindo, ao final que:

O tratamento glamouroso que a mídia e muitos intelectuais atribuíram à globalização e às chamadas cidades globais foi dando lugar, com o passar do tempo e com a apropriação capitalista das novas tecnologias, a uma realidade cruel: aumento do desemprego, precarização das relações de trabalho, recuo nas políticas sociais, privatizações e mercantilização de serviços públicos, aumento da desigualdade social. Diferentemente da desigualdade social ou inserção social precária existentes anteriormente à globalização, após sua dominação hegemônica, ganha destaque uma marca, a da exclusão social: bairros são esquecidos, cidades são esquecidas, regiões são esquecidas e isso acontece, até mesmo, com países, que são ignorados já que não contam para a nova ordem (MARICATO, 2009, p. 4).

Sobre as cidades brasileiras, ao olhar os desfavorecidos e abordar a tutela jurídica das favelas, Celso Antônio Pacheco Fiorillo compreende que:

As cidades do Brasil [...] foram construídas a partir do século XVI em face da enorme extensão da costa e da necessidade de nela estabelecer, para sua defesa, os primeiros núcleos de povoamento e principalmente diante dos objetivos de Portugal, que "antes cuidava de explorar que colonizar", conforme observa Fernando Azevedo. Daí ter sido praticamente imposto aos conquistadores da terra o sistema de povoação marginal, levando os mesmos "a semear de vilas e colônias o litoral vasto, nas enseadas e ancoradouros que oferecessem abrigo seguro às suas naus, galeões e caravelas" [...]. De qualquer maneira é importante registrar que as novas cidades seguiram um modelo uniforme: via de regra um tabuleiro de linhas retilíneas que definiam uma série de quarteirões iguais, quase sempre quadrados. No centro da cidade, suprimiam-se ou reduziam-se alguns quarteirões, conseguindo-se uma praça sobre a qual eram construídos edifícios importantes, a saber, a igreja, o paço municipal, as casas dos mercadores e dos colonos mais ricos (FIORILLO, 2009, p. 1-2).

Essa ótica dos mais desfavorecidos é percebida tendo como ponto de vista a mulher no espaço urbano, em especial, nesse período de nova conformação do núcleo familiar, a saber:

A ocupação de espaços materiais e imateriais nas cidades é diferente de acordo com cada camada social. Cada classe sente e percebe a cidade de uma forma distinta, assim como cada gênero e raça. [...] No Brasil, começaram a ocorrer transformações estruturais na sociedade com o advento e o desenvolvimento do capitalismo, em correlação com um processo de urbanização que se consolida na segunda metade do século XX [...]. As cidades se tornam o principal palco das relações e interações sociais no Brasil. Entretanto, a 
violência contra a mulher persiste em uma ótica privada, como uma questão relacionada ao interior do lar, visto que, apesar da cidade ter emergido como o principal ambiente onde ocorrem as relações sociais, este espaço era (e ainda é) destinado em grande parte apenas aos homens. A partir dessa concepção, identificamos que a violência praticada contra a mulher não era tratada como uma questão pública, mas como um assunto privado, pois situada no espaço doméstico e internamente às relações conjugais e familiares (BELLO; BELEZA, 2019, p. 744-746).

Guardadas as proporções, considerando a geografia e a extensão territorial do Brasil, algumas situações de moradia e organização das cidades não repetiram as mazelas do Velho Mundo, muito embora as habitações coletivas e cortiços possam ser, ainda, encontrados no desenho urbano de cidades históricas como Rio de Janeiro, Recife e Salvador, entre outras. Diz Ponte Neto (2008, p. 37-39) que:

No Brasil, entretanto, implantou-se uma estrutura administrativa por meio de adaptações das Ordenações Manuelinas e Filipinas às condições da colônia, principalmente quanto à organização municipal. Ademais, o Brasil caracterizase para a metrópole como fonte de exploração econômica [...]. Por isso, não é difícil explicar que a política e o aparelho institucional e administrativo constituídos objetivavam a manutenção de situação de dependência à metrópole [...]. Nesse sentido histórico e econômico, Portugal não demonstrou preocupação em estabelecer políticas de povoamento ordenado. Ao contrário, as cidades brasileiras foram geradas à revelia de planejamento.

Essa herança da desorganização e falta de planejamento das cidades espelhou o desenvolvimento urbano no Brasil, somada aos problemas trazidos pelas sociedades de consumo, crises econômicas e outros fatores políticos e sociais que acumularam um passivo ambiental gravoso, ao qual, necessária a intervenção do Estado para equilibrar as relações de trabalho, de disciplina urbanística e, ao final, da proteção do ambiente urbano em seu sentido mais amplo. A modificação da base econômica, passando de um estado extrativista, predominantemente rural, para um modelo capitalista e industrial, não foi precedida de uma organização que pudesse evitar o caos urbano hoje instalado, que culmina atualmente com um movimento inverso: as pessoas adquirem pequenas propriedades rurais ou mudam-se para cidades menores porque é inviável a habitação nas grandes metrópoles ou centros urbanos. Para Rech e Rech (2016, p. 40):

O modelo atual de cidade apenas ampliou o projeto das Ordenações, sem uma preocupação epistêmica e sustentável. As periferias e a área rural continuam sem regras de ocupação, mesmo após o advento do Estatuto da Cidade, que manda planejar todo o território do município. O direito português, na realidade, valorizava muito os espaços públicos, os prédios institucionais como a igreja, a prefeitura, o pelourinho, etc. Os portugueses buscavam sempre um equilíbrio entre os interesses individuais e o coletivo nos centros urbanos que implantavam. 
A situação das áreas urbanas reclama, ainda nos dias atuais, um zoneamento específico que contemple e organize a diversidade de pessoas e atividades, de forma a possibilitar um convívio saudável, harmonioso, que permita uma condição mínima de proteção ambiental, que evite a degradação humana, organizando o território de forma ordenada, e assente a realidade existente em cada um dos municípios, por meio de decisões políticas tomadas em conjunto com as cidades vizinhas, Estado e União. Em regra, a desorganização dos centros urbanos consolida diversas violações aos direitos fundamentais, necessitando, na maioria dos casos, a intervenção do Poder Judiciário para resguardá-los. Para Veiga (2008, p. 138):

O crescimento da população e da produção não deve levar a humanidade a ultrapassar a capacidade de regeneração dos recursos e de absorção dos desejos. Nos países do centro, tanto a produção quanto a reprodução já deveriam estar voltadas apenas à reposição. $O$ crescimento físico deveria cessar, com continuidade exclusiva de alterações qualitativas. Desenvolvimento sustentável quer dizer, para Daly, desenvolvimento sem crescimento.

No ordenamento pátrio, a Constituição Federal de 1988 traduz importante papel na organização urbana, trazendo as diretrizes que foram regulamentadas por normas infraconstitucionais, as quais, vigentes até os atuais dias, impulsionaram importantes alterações na utilização do solo urbano, sem, contudo, resolver a totalidade dos problemas urbanos existentes. $\mathrm{O}$ artigo $24^{1}$ da $\mathrm{CF} / 88$ contempla as competencias que

\footnotetext{
1 “Art. 24. Compete à União, aos Estados e ao Distrito Federal legislar concorrentemente sobre:

I - direito tributário, financeiro, penitenciário, econômico e urbanístico;

II - orçamento;

III - juntas comerciais;

IV - custas dos serviços forenses;

V - produção e consumo;

VI - florestas, caça, pesca, fauna, conservação da natureza, defesa do solo e dos recursos naturais, proteção do meio ambiente e controle da poluição;

VII - proteção ao patrimônio histórico, cultural, artístico, turístico e paisagístico;

VIII - responsabilidade por dano ao meio ambiente, ao consumidor, a bens e direitos de valor artístico, estético, histórico, turístico e paisagístico;

IX - educação, cultura, ensino, desporto, ciência, tecnologia, pesquisa, desenvolvimento e inovação;

$\mathrm{X}$ - criação, funcionamento e processo do juizado de pequenas causas;

$\mathrm{XI}$ - procedimentos em matéria processual;

XII - previdência social, proteção e defesa da saúde;

XIII - assistência jurídica e Defensoria pública;

XIV - proteção e integração social das pessoas portadoras de deficiência;

$\mathrm{XV}$ - proteção à infância e à juventude;

XVI - organização, garantias, direitos e deveres das polícias civis.

$\S 11^{\circ}$ No âmbito da legislação concorrente, a competência da União limitar-se-á a estabelecer normas gerais.

$\S 2 \circ$ A competência da União para legislar sobre normas gerais não exclui a competência suplementar dos Estados.
}

182 R. Opin. Jur., Fortaleza, ano 19, n. 31, p.175-195, maio/ago. 2021 
são concorrentes pela União, pelos Estados e pelo Distrito Federal, na edição de normas gerais de direito urbanístico. Já o artigo $182^{2}$ da Carta Magna, que trata da Política Urbana, há previsão de que o município deverá ordenar a política de desenvolvimento urbano, garantindo o bem-estar de seus habitantes, muito embora "[...] o processo de urbanização no Brasil está fora de controle das autoridades, apesar de a Constituição de 1988 ter resgatado a noção da função social da propriedade, renovando antigos princípios e institutos jurídicos.” (RECH; RECH, 2016, p. 41). Sobre a disposição no texto constitucional acerca da política urbana, Antunes (2015, p. 90-91) assinala que:

Com efeito, a Constituição Federal estabelece em diversos artigos que as áreas urbanas devem merecer tratamento legal específico, havendo uma esfera de competência da União (Artigo 21, XX), uma de competência concorrente com os Estados (Artigo 24, I), uma exclusiva dos Estados (Artigo 25, § 30). Além disso, existem as competências exclusivas dos municípios, vinculadas ao interesse local (Artigo 30, I, II e VIII) que se aperfeiçoam com o poder outorgado aos municípios para suplementar as legislações federal e estadual no que couber. Isso para que não se esqueça de que o planejamento da ocupação do solo urbano é uma atribuição do poder local.

Dessa afirmação constitucional, sobreveio o Estatuto da Cidade, com a promulgação da Lei Federal no 10.257/2001, que tratou de regulamentar o capítulo da Constituição Federal de 1988 que trata da política urbana, fixando princípios básicos, os quais têm propósito de nortear as ações dos municípios na gestão de seu território, tendo como ferramenta básica o Plano Diretor, que contempla a gestão democrática da cidade, leia-se, por meio da participação dos munícipes, por audiências públicas ou pelas associações representativas de classe. Milaré (2005, p. 66) ensina que:

§ 30 Inexistindo lei federal sobre normas gerais, os Estados exercerão a competência legislativa plena, para atender a suas peculiaridades.

$\S 4^{\circ}$ A superveniência de lei federal sobre normas gerais suspende a eficácia da lei estadual, no que lhe for contrário." (BRASIL, 1988, online).

2 "Art. 182. A política de desenvolvimento urbano, executada pelo Poder Público municipal, conforme diretrizes gerais fixadas em lei, tem por objetivo ordenar o pleno desenvolvimento das funções sociais da cidade e garantir o bem-estar de seus habitantes.

$\S 1^{\circ} \mathrm{O}$ plano diretor, aprovado pela Câmara Municipal, obrigatório para cidades com mais de vinte mil habitantes, é o instrumento básico da política de desenvolvimento e de expansão urbana.

$\S 2 \circ \mathrm{A}$ propriedade urbana cumpre sua função social quando atende às exigências fundamentais de ordenação da cidade expressas no plano diretor.

$\S 3^{\circ}$ As desapropriações de imóveis urbanos serão feitas com prévia e justa indenização em dinheiro.

$\S 4^{\circ}$ É facultado ao Poder Público municipal, mediante lei específica para área incluída no plano diretor, exigir, nos termos da lei federal, do proprietário do solo urbano não edificado, subutilizado ou não utilizado, que promova seu adequado aproveitamento, sob pena, sucessivamente, de:

I - parcelamento ou edificação compulsórios;

II - imposto sobre a propriedade predial e territorial urbana progressivo no tempo;

III - desapropriação com pagamento mediante títulos da dívida pública de emissão previamente aprovada pelo Senado Federal, com prazo de resgate de até dez anos, em parcelas anuais, iguais e sucessivas, assegurados o valor real da indenização e os juros legais." (BRASIL, 1988, online). 
Permitir que as comunidades cuidem de seu próprio ambiente: a ação comunitária no cuidado com o meio ambiente deve ser favorecida. As comunidades e grupos locais constituem os melhores canais para as pessoas expressarem suas preocupações e tomarem atitudes relativas à criação de bases sólida para sociedades sustentáveis. No entanto, essas comunidades precisam de autoridade, poder e conhecimento para agir. As pessoas que se organizam para trabalhar pela sustentabilidade em suas próprias comunidade podem constituir uma força efetiva, seja a comunidade rica ou pobre, urbana, suburbana ou rural.

$\mathrm{Na}$ prática, ouvida a sociedade em audiências públicas, a criação do Plano Diretor, por meio de lei complementar municipal própria para esse fim, possibilita ajustar e regulamentar as ações do poder público, dos empreendedores e dos munícipes, com vistas ao cumprimento do regramento nele imposto, já que fruto das expectativas da população envolvida, trazida à discussão pela premissa da participação popular. Para isso, é necessário exacerbado comprometimento do poder público em gerir suas ações, com práticas fiscalizatórias, educativas e preventivas, administrando o contexto urbano e rural que está pronto no perímetro do município e evitando seu desvirtuamento, a partir do atendimento contínuo ao postulado nos princípios constitucionais e na supremacia do interesse público e ambiental.

As demais leis municipais, sejam anteriores, sejam posteriores, deverão estar em consonância com o Plano Diretor vigente, já que são instrumentos jurídicos que se prestam a garantir sua efetividade. Pode-se afirmar que, da legislação municipal existente, o Plano Diretor é o que mais afeta a vida dos munícipes, quer seja na limitação do direito de propriedade, nos aspectos tributários e fiscais e, principalmente, na busca pela qualidade de vida, bem-estar, bem como, pela dinâmica de um modelo de cidade inteligente, que seja inclusiva e não o seu inverso. Rech e Rech $(2016$, p. 390) lembram que:

Além disso, o Plano Diretor é uma lei hierarquicamente superior por duas razões fundamentais: primeiro, que é lei complementar e, em segundo lugar, que é uma lei especial que exige um processo complexo de aprovação, passando primeiro pela instância direta da população.

O ordenamento jurídico pátrio, em todos os seus níveis, reconhece e cria instrumentos que permitem a gestão das áreas rurais e urbanas, das metrópoles e dos grandes centros urbanos, de forma a gerir um crescimento e desenvolvimento pautado na sustentabilidade, consolidando a aplicação e a garantia dos direitos fundamentais e sociais, com a distribuição entre todos os envolvidos dos ônus e dos benefícios decorrentes da urbanização, cientes de que o inverso poderá inviabilizar a própria manutenção da vida nas cidades, repetindo-se o caos vivido no período da Revolução Industrial, cujas perspectivas foram antes referidas. 
O impacto ambiental decorrente da existência do homem é inevitável, quer seja no campo, quer seja nos centros urbanos. A economia fomenta esse impacto, quando planejada de forma dissociada do passivo ambiental causada pela falta de consciência no consumo de bens e serviços e a política, por vezes, ao invés de criar ou aplicar os instrumentos necessários à gestão dessa demanda, o faz em sentido inverso, premiando o desenvolvimento descompromissado com a sustentabilidade ambiental. Leff (2009, p. 38), ao tratar da racionalidade ambiental, afirma que:

Os custos sociais e ambientais da promoção do crescimento eminentemente econômico não são profundamente avaliados no que tange aos impactos de destruição dos recursos naturais, o que implica na própria perda do potencial econômico dos ecossistemas naturais, porquanto da realização do manejo integrado dos recursos e da descoberta dos recursos potenciais.

Essa problemática não é sentida apenas no Brasil. A título comparativo, a Itália experimenta diversos desdobramentos decorrentes do desenvolvimento urbano e a busca da sustentabilidade, em um passivo urbanístico e ambiental que data ao período romano, passando por grandes guerras e catástrofes ambientais de toda a sorte. Mesmo em um país de primeiro mundo, há uma busca constante por instrumentos de desenvolvimento sustentável que sejam coesos e afinados com a tutela dos direitos fundamentais, reconhecendo aos citadinos a cidade e o próprio direito à cidade. Nesse sentido, Scala (2018, p. 794) reconhece que:

Si è recentemente osservato che la città tende a eludere il diritto, che si deforma e modifica davanti a la pression de la ville e alle richieste degli attori urbani, essendo così capace di tradursi in regole malleabili e indicative più che rigide e imperative, subendo l'ordinamento generale le naturali pressioni di gruppi d'interesse e di una pluralità di ordinamenti giuridici originari. ${ }^{3}$

Essas pressões naturais de grupos de interesse sentidas pela autora na experiência italiana são percebidas, na realidade, nas cidades brasileiras, em um habitual embate entre a economia, a política e o direito, esse último, visto no seu aspecto mais amplo, da proteção do bem ambiental e dos direitos fundamentais. O Brasil está em desenvolvimento, guarda importantes reservas ambientais em vasto território, e o reflexo disso é que as cidades brasileiras experimentam o inverso da riqueza existente, evidenciando toda a sorte de adversidades sociais, como a miséria, a falta de saneamento básico, de trabalho, educação e saúde, dentre outros aspectos, de forma que se sentem tentados por propostas de empreendedores interessados em instalar parques fabris ou fomentar o crescimento urbano, com a abertura de bairros e loteamentos, deixando os

\footnotetext{
${ }^{3}$ Tradução livre dos autores: "Recentemente, constatou-se que a cidade tende a fugir da lei, que se deforma e se modifica diante da pressão das vilas e as demandas dos atores urbanos, podendo assim se traduzir em regras maleáveis e indicativas ao invés de rígidas e imperativo, sujeitando a ordem geral às pressões naturais de grupos de interesse e uma pluralidade de sistemas jurídicos originais".
} 
entes políticos de atentar para um projeto de cidade que englobe a todos. Na Itália, Spasiano (2005, p. 189) observa que "esigenze di "sviluppo economico, particolarmente avvertite in talune Regioni italiane, potrebbero spingere le stesse a non dar luogo all'applicazione di restrittive misure di protezione dell'ambiente, al fine di "legittimare" più libere iniziative imprenditoriali o di altro genere" ${ }^{4}$, constatação que muito se assemelha à problemática vivida nas cidades brasileiras.

Assim, evidenciada a violação de direitos fundamentais ou o desvirtuamento das diretrizes do Plano Diretor, cabe ao Poder Judiciário, em última instância, restabelecer a situação havida, de forma que, quando provocado pela sociedade ou seus representantes, pode promover a proteção do bem ambiental. Capelli (2011, p. 41)assevera que:

Poiché i problemi di carattere ambientale sono divenuti ultimamente più dificili e complessi, le azioni delle associazioni ambientaliste e delle organizzazioni protezionistiche dovranno sempre più intensificarsi ed afinarsi anche grazie agli apporti di coloro che dispongono delle conoscenze specialistiche e delle capacità tecniche indispensabili per risolverli. Tra questi specialisti, che sostengono ed aiutano le predette associazioni e rganizzazioni, i giuristi svolgono un ruolo particolare, perché sono essi che, alla fine, devono spingere i Giudici a seguire correttamente gli orientamenti virtuosi imposti dalla normativa ambientale. ${ }^{5}$

Fica evidente assim que a proteção do ambiente urbano deveria encontrar esteio na prestação jurisdicional que, quando provocada, avocaria para si a obrigação de restabelecer os princípios constitucionais violados por decisões de cunho político e econômico, afastando a discricionariedade do administrador público ou seu propósito de crescimento desmedido que compromete o bem ambiental e a qualidade de vida do ser humano.

\footnotetext{
4 Tradução livre dos autores: "As necessidades de "desenvolvimento econômico", particularmente sentidas em algumas regiões italianas, poderiam levá-lo a não dar origem à aplicação de medidas restritivas de proteção ambiental, a fim de "legitimar" iniciativas de livres negócios ou outros".

${ }^{5}$ Tradução livre dos autores: "Como os problemas ambientais têm se tornado mais difíceis e complexos ultimamente, as ações das associações ambientalistas e organizações protecionistas terão de se intensificar e melhorar também graças às contribuições de quem tem o conhecimento especializado e as habilidades técnicas necessárias para resolvê-los. Dentre esses especialistas, que apoiam e auxiliam as referidas associações e organizações, os juristas desempenham um papel particular, porque são eles que, no final, devem pressionar os Juízes a seguirem corretamente as diretrizes virtuosas impostas pela legislação ambiental”.
} 


\section{O DESAFIO DA PROTEÇÃO JURISDICIONAL DO AMBIENTE URBANO E OS ENTRAVES IDEOLÓGICOS}

A afirmação da característica não patrimonial do ambiente e, por conseguinte, de sua impossibilidade de apropriação pelo indivíduo fica confirmada nos mais diversos ordenamentos. Na prática, sabe-se que a proteção ambiental é subjugada pela política, pela economia e por aqueles que não compreendem, qualquer que seja a razão, a finitude do recurso ambiental. $O$ risco de um colapso já é sentido nos povos que experimentam malversações ambientais, períodos prolongados de estiagens, que inviabilizam o cultivo ou a criação, ou quaisquer outras adversidades decorrentes do clima e da poluição, esses sim, que não se apegam aos limites de fronteiras entre as nações ou ao seu viés político. Nas grandes áreas urbanas, fica inviabilizada a vida através da poluição sonora e atmosférica, dos córregos, rios e parques, além de patologias advindas do estresse decorrente da vida nos grandes centros, permeada de intenso tráfego de veículos, marginalidade e outras intercorrências que resultam do crescimento desigual, desordenado e desenfreado. Dorr e Damacena (2018, p. 12) compreendem que:

A crise ecológica, manifestada pelo crescimento desenfreado de problemas ambientais, decorrentes de poluição, degradação ambiental, acúmulo de lixo, desmatamento, entre outros, também contribuiu à necessidade de desenvolvimento de mecanismos jurídico-processuais que pudessem tutelar o ambiente em todas suas peculiaridades.

Deve-se esclarecer, nesse momento, a compreensão social acerca da liberdade do citadino em viver na cidade e da própria cidade, que foi, por muito tempo, objeto de cobiça de empreendedores e políticos, que usam de forma desmedida seu poder em prol dos interesses de uma minoria. Barroso (1992, p. 41) aponta a seguinte fragilidade do sistema:

O terceiro-mundismo tem suas vantagens. Uma delas é a de tornar-nos cosmopolitas. Aqui, ninguém sobrevive intelectualmente se não tiver os olhos postos no conhecimento que se produz além-mar. Desde pequenos, aprendemos o Brasil, a Europa e os Estados Unidos. O primeiro mundo, ao revés, notadamente na sua expressão norte-americana, tende a ser extremamente provinciano. Na melhor das hipóteses, um incipiente universalismo percorrerá uma trajetória egocêntrica. Até aí, nada de muito grave. Cada um há de perceber o mundo do seu ponto de observação. A deformação começa quando, por um equivocado processo de transferência, o habitante da periferia adquire a ideologia do grande centro. E o que é pior: assimila-a acriticamente, sem ensaiar sequer adaptações mínimas indispensáveis. Em seguida, envergonhado pelo atraso da periferia, faz o discurso avançado, impacientando-se com a plateia retrógrada, que não o acompanha nem o entende. Tem sido assim desde sempre, do colonialismo 
político ao colonialismo cultural. Passa-se do arco e flecha ao fuzil, sem percorrer os caminhos do amadurecimento. Neste momento de afirmação das preocupações ecológicas, é bom reavivar na memória o retrato distorcido descrito acima. É que, por diversas razões, a questão ambiental teve seu berço e evolução no primeiro mundo.

Por sua vez, Paolo Maddalena compreende que a tutela jurídica ambiental depende de diversos componentes, como o interesse em jogo, a vontade política e mesmo a própria questão filosófica em conceituar o homem, a sociedade, a natureza e o ambiente. Diz o autor:

Tutto dipende dalla forza dell'interesse in gioco. Ai valori si sostituisce la volontà di chi riesce ad influenzare la maggioranza politica.Esiste, è vero, la Costituzione ed i valori che questa contiene, ma si deve tener conto che anche le norme costituzionali vanno interpretate e che, d'altro canto, la Costituzione può essere agevolmente cambiata.Probabilmente il diritto ha perso molta della sua forza.È diventato un diritto mite, e può persino dubitarsi che esso sia sempre in grado di assicurare la tutela degli interessi generali. D'altro canto, la stessa politica, profondamente malata, sembra dimentichi spesso che il suo compito è quello di perseguire, non interessi personali o di lobbyes, ma il bene comune della Nazione. Intanto i valori tradizionali, ed in particolare il valore della giustizia, sembrano regredire di fronte all'avanzata, possente e distruttiva insieme, dell'interesse economico. ${ }^{6}$ (MADDALENA, 2007, p. 1).

A tomada de uma decisão ambiental no âmbito da política ou no judicial encontra dois pontos de referência. O primeiro está voltado aos direitos e deveres ambientais, sentidos por aqueles que são os sujeitos aos quais é direcionada a norma legal ou a decisão prolatada, que carregam ainda aspectos subjetivos de natureza econômica, política e social. O segundo ponto é o que trata da sociedade, detentora dos direitos constitucionais havidos em textos legais e tratados internacionais, que são protegidos de qualquer forma de desconexão ou retrocesso, mas, nas decisões havidas, são ponderados ou relativizados de acordo com a compreensão e a importância que o administrador público ou o julgador dá ao ambiente.

Basta observar uma decisão jurídica de cunho ambiental, com o dinamismo dessa ciência, que envolve da biologia à medicina, passando pelas engenharias, ciência política, economia, ciências humanas, sociais e até mesmo as exatas, expõe a ausência de

\footnotetext{
${ }^{6}$ Tradução livre do autor: "Tudo depende da força do interesse em jogo. Os valores são substituídos pela vontade daqueles que conseguem influenciar a maioria política. Existe, é verdade, a Constituição e os valores que ela contém, mas deve-se considerar que as regras constitucionais também devem ser interpretadas e que, por outro lado, a Constituição pode ser facilmente alterada. Provavelmente, o direito perdeu muito de sua força. Tornou-se um direito moderado, e pode-se até duvidar que seja sempre capaz de garantir a proteção dos interesses gerais. Por outro lado, a própria política, profundamente doente, parece frequentemente esquecer que sua tarefa é buscar, não interesses pessoais ou lobistas, mas o bem comum da Nação. Enquanto isso, os valores tradicionais, e em particular o valor da justiça, parecem regredir diante do avanço poderoso e destrutivo do interesse econômico".
}

188 • R. Opin. Jur., Fortaleza, ano 19, n. 31, p.175-195, maio/ago. 2021 
um permissivo que possibilite ao operador do direito decidir atrelado à lógica, quando a racionalidade da ciência jurídica é a racionalidade da própria vida, em muito divergindo de uma decisão política, que, além de injustificada, pouco ou nada guarda de comprometimento com os preceitos constitucionais.

Dos entes públicos responsáveis pela gestão dos municípios, esperam-se decisões políticas voltadas ao esforço integrado entre os povos, as classes sociais e os municípios que compõem determinada região, na construção do bem-estar social, focado em um planejamento do crescimento que assegure a manutenção do ambiente. Os mandatos políticos deverão atentar para essa continuidade, sem esquecer os erros e os aprendizados do passado, diminuindo as diferenças econômicas, promovendo a constante defesa dos bens jurídicos afirmados na esfera constitucional, dentre eles o bem ambiental, no qual, está inserido o ambiente urbano, criando-se uma interconexão entre a defesa da sociedade, o desenvolvimento e o respeito ao direito individual. Ensina Silva (2004, p. 59) o que:

Talvez seja adequado dizer que as grandes transformações, que nos permitem, de uma longa distância, distinguir um período histórico de outro, acontecem mais pela forma como os homens passam, através de um processo lento e imperceptível, a compreender o acervo cultural acumulado pelas épocas precedentes, mais do que pela descoberta de materiais novos e até mesmo de circunstâncias desconhecidas. Este ponto é fundamental para a compreensão histórica.

Os empreendedores devem seguir propósitos ambientais que justifiquem a existência e a própria manutenção de seus empreendimentos. Pensar em um investimento que irá escusar-se nas lacunas das normas ambientais para a sua operação implicará numa conduta não mais aceita pela sociedade, fadando-se ao fracasso. As normas deverão ser interpretadas, sempre, tendo como norte tanto a supremacia do bem ambiental quanto da sociedade. Não se permite o crescimento econômico lastreado na degradação ambiental. Ao longo dos séculos, operou-se a exclusão social, colocando os mais pobres em cinturões de miséria nos entornos da cidade. No entanto, a degradação do ambiente urbano não faz diferenciação entre o rico e o pobre, o jovem e o velho. $\mathrm{O}$ ar que se respira é o mesmo para todos. As crises ambientais movem legiões de refugiados, esvaziam povoados e inviabilizam a manutenção de valores mínimos da sociedade.

O desafio da jurisdição nos tempos atuais, ainda mais aquela de cunho ambiental, passa pela necessidade de confiança da sociedade naqueles que detêm a tarefa da aplicação do direito, estabelecendo muito mais que a vontade da lei, em um propósito de obter uma jurisdição que atente na solução dos conflitos sociais, no dinamismo e na evolução da compreensão jurídico-política-processual, com o propósito de alcançar, ao final, a manutenção da vida pelas vias da proteção ambiental. 
É preciso afastar-se da ideia da busca da certeza, impregnada no direito material e processual, aceitando a probabilidade e a razoabilidade, como informadoras da ciência, constatado o dinamismo da questão ambiental. $\mathrm{Na}$ atualidade, não cabe a afirmação de que "juridicamente, a vontade concreta da lei é aquilo que o juiz afirma ser a vontade concreta da lei" (CHIOVENDA, 2000, p. 46), já que hoje, tudo parte de uma interpretação, de uma hermenêutica sistemática e da construção de definições multidisciplinares pela sociedade, na qual está inserido também o operador do direito. O Direito passa, então, a incorporar outros valores, que são plurais, multifacetados, adotando uma nova posição jurídica e exigindo, como causa-efeito, que o Estado celebre com seus cidadãos um pacto de proteção a todas formas de vida, tendo como a premissa principal a manutenção da própria existência, buscando a resolução das demandas também por meio da jurisdição. O próprio Bobbio (2004, p. 34) considera que:

O campo dos direitos sociais, finalmente está em contínuo movimento: assim como as demandas de proteção social nasceram com a revolução industrial, é provável que o rápido desenvolvimento técnico e econômico traga consigo novas demandas, que hoje não somos capazes nem de prever.

Enquanto a ideologia pode assentar um entrave nesse desafio para a proteção do ambiente urbano, tanto no aspecto político, nas desmedidas decisões administrativas voltadas a fomentar o crescimento desenfreado, quanto no judicial, que encontra, por vezes a ressalva de que o processo está muito mais voltado à verificação da correta tramitação do que a própria resolução do litígio, a hermenêutica pode contribuir de forma ímpar, desvelando uma nova compreensão dos fatos e da necessidade de que as decisões sejam tomadas em prol da coletividade e da manutenção do bem ambiental, como forma de garantir a vida para as gerações presentes e futuras.

\section{AS PERSPECTIVAS PARA O DESENVOLVIMENTO DO AMBIENTE URBANO E SUA PROTEÇÃO JURISDICIONAL}

As cidades não se organizam, nem prosperam se desconsiderados os ambientes naturais de seu entorno. Além disso, devem prover seus habitantes dos recursos necessários para a subsistência, de forma a viabilizar sua sobrevivência. Para Scala (2018, p. 787):

La nozione di città non trova una definizione generale nel diritto positivo. Sembra, tuttavia, da questo presupposta e intesa nei termini in cui si trova da decenni formulata nel pensiero urbanistico: come insieme e intreccio degli interessi, delle istanze, delle attività, delle relazioni della società radicata nel rispettivo territorio nelle sue molteplici e articolate componenti, con 
superamento di ogni sua considerazione in termini squisitamente fisici e materiali, di semplice ambito geografico e di realtà edificata. ${ }^{7}$

Mesmo que não seja pacífica a definição de cidade, é possível conceber a ideia da fragilidade de um ambiente urbano, independentemente da densidade populacional, norteada pela tênue demarcação do embate entre os interesses individuais e coletivos, alicerçada na preocupação da preservação dos recursos naturais da qual depende para a própria estabilidade social. As diferentes condições sociais e econômicas dos citadinos apontam para a necessidade de uma linha de ação que seja comum, justa e inclusiva, baseada nos princípios e diretrizes que assentam a formação de seu Plano Diretor. O inverso significa restabelecer o caos já experimentado no contexto histórico que permeou o período da Revolução Industrial e do pós-guerra, com o agravante de que, naqueles tempos, o elemento do consumismo desenfreado não era conhecido por aquela geração de miseráveis que compunham a maior parte da população.

Para Rech e Rech (2016, p. 19), “a cidade é uma construção antropológica e que deve transcender o próprio tempo, pois deve levar em consideração o passado, presente e futuro". O regramento pátrio existente, em especial o Estatuto da Cidade e também os Planos Diretores que dele decorrem são importantes instrumentos para o desenvolvimento saudável e sustentável do ambiente urbano, munidos de uma sistemática que permite considerar as premissas de sua organização. Os autores antes citados afirmam que "os prefeitos até hoje ainda não descobriram que cidades planejadas não precisam de dinheiro, mas de cabeças pensantes e capazes de usar a lei como instrumento efetivo de planejamento [...]." (RECH; RECH, 2016, p. 41).

Com o Estatuto da Cidade, inaugura-se o comprometimento do exercício da propriedade urbana em uma feição ambiental, que traz a obrigação do direito à vida e à sustentabilidade, sob a ótica do Direito Ambiental. Para Fiorillo (2010, p. 450):

Sendo a maior importante norma regulamentadora do meio ambiente artificial, o Estatuto da Cidade, ao ter como objetivo ordenar o pleno desenvolvimento das funções sociais da cidade e da propriedade urbana, mediante algumas diretrizes gerais, criou a garantia do direito a cidades sustentáveis.

No entanto, a existência das normas por si não alcança emprestar a efetividade necessária para que haja, efetivamente, a proteção jurisdicional do ambiente urbano, já que diversos são os atores incumbidos dessa proteção. No trato ambiental, a atividade jurisdicional exige postura ativa e comprometida com a proteção da natureza. Ainda

\footnotetext{
${ }^{7}$ Tradução livre dos autores: "A noção de cidade não encontra uma definição geral no direito positivo. Parece, no entanto, a partir dea suposição e entendida nos termos em que vem sendo formulada há décadas no pensamento urbanístico: como um todo e entrelaçamento de interesses, solicitações, atividades, relações da empresa enraizada no respectivo território em seus múltiplos e componentes articulados, superando todas as suas considerações em termos puramente físicos e materiais, de um contexto geográfico e de construção simples".
} 
que evidente a necessidade do despertar de uma consciência ambiental a ser disseminada em toda a sociedade, para que se efetive, dependerá de outros pilares, como a educação, a fiscalização e o aprimoramento dos modelos de produção sustentável, premissas que cabem, antes de tudo, aos entes políticos, também atores dessa proteção.

Nota-se que a esperança de tutela ambiental, como forma de proteção do ambiente urbano, deposita-se na atividade jurisdicional. $\mathrm{O}$ exame da proteção ambiental sob o prisma unicamente do direito material, leia-se o Estatuto da Cidade e os Planos Diretores, esbarra na ausência de efetividade das normas de seu resguardo, porque faltam elementos que concretizem tal proteção que, em grande parte dos casos, realiza-se somente e por meio da jurisdição.

A proteção ambiental, ainda que não seja plenamente compreendida por todos os atores sociais é, antes de mais nada, um dever de todos. Essa proteção, quando realizada pela atividade jurisdicional, representa a afirmação do cuidado do próprio Estado com esse bem que é indispensável para manter a continuidade da vida e a própria pacificação dos conflitos sociais, são inerentes aos ambientes urbanos em momentos de crise de recursos ambientais e da supressão, total ou parcial, de direitos individuais ou coletivos. Partindo da questão ambiental, é preciso perceber que a proteção jurisdicional do ambiente urbano também será determinada e sofre influência pela forma como o operador compreende a vida e a natureza como um todo.

O maior desafio está em promover a consonância desses atores na importância da proteção do ambiente, inclusive o urbano, inaugurando-se a perspectiva de conscientização e comprometimento de suas ações, em um novo patamar que permita a manutenção da vida nas cidades e consolide a necessária sustentabilidade para as atuais e futuras gerações.

\section{CONCLUSÃO}

A preocupação da sociedade com a proteção ambiental e, em especial, também do ambiente urbano, foi afirmada no texto constitucional pátrio e nas diversas normas infraconstitucionais, das quais, destacou-se o Estatuto da Cidade, norma federal e os Planos Diretores, que são leis complementares municipais. Essa evolução também parte da percepção da finitude dos recursos e dos desacertos havidos especialmente, na migração aos centros urbanos, havida em especial na Revolução Industrial, fazendo com que a sociedade reclame a manutenção do bem ambiental em seu mais amplo sentido, como um pressuposto para a manutenção da vida.

Essa mesma sociedade que reclama seja assegurada a manutenção da vida, espera do Direito e dá a ele importante papel como instrumento de efetivação desse resguardo, o que faz por meio da jurisdição. No entanto, as normas materiais e processuais 
existentes no ordenamento jurídico brasileiro não permitem garantir plenamente a proteção ambiental, já que o componente ideológico que permeia o ato de decidir pode, por vezes, afastar ou minimizar a proteção reclamada, percebendo-se que a tutela jurisdicional também será determinada na forma como o operador compreende a vida e a natureza como um todo. $\mathrm{O}$ mesmo é sentido nas decisões políticas, que recebem forte pressão da economia, dos empreendedores e de parcela da sociedade que reclama o desenvolvimento a qualquer custo.

A abordagem trazida confirma a crise entre o Direito e a ideologia ambiental, constata que a existência de normas constitucionais e leis ordinárias hábeis à proteção do ambiente urbano carecem de efetividade, já que são dependentes de decisões advindas da política, por vezes, complementadas ou modificadas por decisões judiciais, que, no cotejo, acenam para componentes ideológicos diversos à finitude dos recursos e a proteção ambiental almejada pela sociedade, o que reclama uma nova postura, hábil a efetivar os reclames em prol do bem ambiental, proporcionando, aqui, elementos que podem servir de base para repensar um projeto de cidade inclusiva.

A dinâmica da vida, em seus múltiplos desdobramentos, não é certa nem previsível. Nessa perspectiva, uma ciência que se propõe a resolver conflitos da vida haverá de aceitar a probabilidade e a razoabilidade, desgarrando-se dos modelos existentes e trazendo, ao final, uma nova perspectiva à previsão constitucional que proclama a proteção jurisdicional do ambiente urbano.

\section{REFERÊNCIAS}

ANTUNES, Paulo de Bessa. Áreas de preservação permanente urbanas. Revista de Informação Legislativa, Brasília, v. 52, n. 206, p. 83-102, abr./jun. 2015, 2015.

BARROSO, Luís Roberto. A Proteção do meio ambiente na constituição brasileira. Revista de Direito da Procuradoria Geral do Estado do Rio de Janeiro, Rio de Janeiro, v. 44, p. 41-75, 1992.

BELLO, Enzo; BELEZA, Larissa Alessandra Santos. As mulheres no espaço urbano brasileiro: o direito à cidade como alternativa a um cenário de violações de direitos humanos. Revista Direito da Cidade, Rio de Janeiro, v. 11, p. 741-764, 2019.

BRASIL. Constituição (1988). Constituição da República Federativa do Brasil. Brasília, DF: Presidência da República, 1988. Disponível em http://www.planalto.gov.br/ccivil_03/Constituicao/Constituicao.htm. Acesso em: 1 mar. 2021.

BOBBIO, Norberto. A era dos direitos. Tradução Carlos Nelson Coutinho. Nova ed. Rio de Janeiro: Elsevier, 2004. 
CAPELLI, Fausto. Ambiente e democrazia: un'integrazione al dibattito. Rivista Giuridica Dell'Ambiente, Milano, p. 41-52, 2011.

CHIOVENDA, Giuseppe. Instituições de direito processual civil. Campinas: Bookseller, 2000.

DORR, Julia Marta Drebes; DAMACENA, Fernanda Dalla Libera. Limites e possibilidades da intervenção judicial em políticas públicas de meio ambiente: uma análise do posicionamento dos tribunais brasileiros no julgamento de ações cicis públicas. Revista Direito Ambiental e Sociedade, Caxias do Sul, v. 8, p. 7-37, 2018.

ENGELS, Friedrich. A situação da classe trabalhadora na Inglaterra. São Paulo: Boitempo, 2008.

FIORILLO, Celso Antônio Pacheco. Natureza jurídica da favela no direito ambiental brasileiro e sua tutela vinculada ao meio ambiente artificial. In: AHMED, Flávio; COUTINHO, Ronaldo (org.). Cidades Sustentáveis no Brasil e sua tutela jurídica. Rio de Janeiro: Editora Lumen Juris, 2009.

FIORILlO, Celso Antônio Pacheco. Curso de direito ambiental brasileiro. São Paulo: Saraiva, 2010.

LEFF, Enrique. Ecologia, capital e cultura: a territorialização da racionalidade ambiental. Petrópolis: Vozes, 2009.

MADDALENA, Paolo. L'ambiente: Reflessioni introduttive per una sua tutela giuridica. Legale. Ambiente e sviluppo. It., 2007, 6 (commento alla normativa). Milano (IT): Wolters Kluwer Italia SRL.

MARICATO, Ermínia. Globalização e política urbana na Periferia do capitalismo. Revista VeraCidade, Salvador, v. 4, n. 4, mar. 2009.

MILARÉ, Édis. Direito do ambiente: doutrina, jurisprudência, glossário. 4. ed. São Paulo: Revista dos Tribunais, 2005.

MUKAI, Toshio. Direito urbano-ambiental brasileiro. São Paulo: Dialética, 2002.

PONTE NETO, José Júlio da. Poder público local e cidadania: atores políticos sociais na construção da democracia participativa no município de Fortaleza: uma análise dos anos de 1990 a 2004. Fortaleza: Universidade de Fortaleza, 2008.

RECH, Adir Ubaldo; RECH, Adivandro. Cidade sustentável, direito urbanístico e ambiental: instrumentos de planejamento. Caxias do Sul: Educs, 2016. 
SCALA, Maria Grazia Della. Lo sviluppo urbano sostenibile e gli strumenti del governo territoriale tra prospettive di coesione e tutela dei diritti fondamentali. Diritto Amministrativo, v. 26, n. 4, p. 787-800, 2018.

SILVA, Ovídio A. Baptista da. Processo e ideologia: o paradigma racionalista. Rio de Janeiro: Forense, 2004.

SPASIANO. Mario Rosario. I soggetti della politica ambientale in Italia. Riv. Giur. Edilizia, Milano, v. 5, p. 185-198, 2005.

VEIGA, José Ely da. Desenvolvimento sustentável: o desafio do século XXI. 3. ed. Rio de Janeiro: Garamond, 2008.

\section{NOTA}

O artigo DESAFIOS E PERSPECTIVAS PARA A PROTEÇÃO JURISDICIONAL DO AMBIENTE URBANO, a ser publicado na Revista Opinião Jurídica, foi elaborado em conjunto pelos coautores, com amplo debate acerca dos objetivos, metodologia e resultados, cabendo ao primeiro coautor, a pesquisa bibliográfica e documental, produção de fichamentos e a digitação do artigo. Pelo segundo coautor, foi realizado a complementação da pesquisa bibliográfica, a revisão dos fichamentos, a adequação do objetivo, metodologia e disposição dos capítulos. Ao último, coube a revisão final do artigo, de sua formatação, elaboração da introdução e das considerações finais.

\section{Como citar este documento:}

BRANDELlI, Ailor Carlos; LUNELli, Carlos Alberto; PRIEUR, Julien. Desafios e perspectivas para a proteção jurisdicional do ambiente urbano. Revista Opinião Jurídica, Fortaleza, v. 19, n. 31, p. 175-195, maio/ago. 2021. 